\title{
Cyclic Nucleotide Changes in Fusion-Arrested Chick Embryo Myoblasts during Differentiation In Vitro
}

\author{
Yoichi Moriyama and Kazuko Murayama \\ Department of Biochemistry, Chiba University School of Medicine, Inohana, \\ Chiba, Japan
}

\begin{abstract}
Changes in intracellular concentrations of adenosine 3', 5'monophosphate (cAMP) and guanosine 3', 5'-monophosphate (cGMP) were investigated in primary cultures of chick embryonic muscle cells grown in the presence of 5'-bromodeoxyuridine (BUdR). Cell fusion was completely inhibited in BUdR-treated cultures; however, the effect was reversed when the BUdR-containing medium was replaced with normal medium. As in control cultures, a significant increase in the ratio of cAMP-to-cGMP was observed during the first few days in both the BUdR-treated and the BUdR-released cultures. The data indicate that cell fusion is not a necessary step for concentration changes in cyclic nucleotides, which means that these changes might be a cause but not an effect of myoblast fusion.
\end{abstract}

Myoblasts of chick embryonic skeletal muscle in appropriate culture conditions form muscle fibers by successive fusion of mononucleated myoblasts into multinucleated myotubes. The myoblast fusion is one of the earliest recognizable phenotypic signs of muscle differentiation, for a burst of synthesis in muscle-specific proteins, such as myosin, actin and creatine kinase occurs after myotube formation $(12,16,17)$.

The intracellular concentration of cyclic nucleotides has been proposed as possibly regulating cell fusion. The correlation between myoblast fusion with endogenous $(8,26,27)$ and exogenous $(22,24)$ adenosine 3', 5'-monophosphate (cAMP) level has been shown in cultured, as well as in developing embryonic muscle cells. Furthermore, our previous data (8) have suggested that in addition to an increase in cAMP, a decrease in guanosine 3', 5'-monophosphate (cGMP) might be involved in regulating cell fusion. From our results, as well as those of previous workers, questions have arisen on how closely the changes in cyclic nucleotides are linked to cell fusion.

In the present study cyclic nucleotide levels were examined in fusion blocked cultures using 5'-bromodeoxyuridine (BUdR) to determine whether cell fusion steps are coupled with cyclic nucleotide changes.

\section{MATERIALS AND METHODS}

Cultures. Cells were prepared from thigh muscles of 12-day old chick embryos by trypsinization, as described previously (8). After minimizing non-myogenic cells by the selective preplating method (14), myogenic cells were inoculated at a cell density of $1 \times 10^{6}$ per dish in a $60 \mathrm{~mm}$ diameter Petri dish (Falcon plastics) coated with $1 \%$ gelatin. Each dish contained 2.5 $\mathrm{ml}$ of culture medium, consisted of $80 \%$ Eagle's minimum essential medium, $15 \%$ horse 
serum and $5 \%$ chick embryo extract, with streptomycin $(50 \mu \mathrm{g} / \mathrm{ml})$ and penicillin $(50 \mathrm{U} / \mathrm{ml})$. Chick embryo extract was prepared from 10-day old embryos. Cultures were incubated at $37^{\circ} \mathrm{C}$ in an atmosphere of $5 \% \mathrm{CO}_{2}, 95 \%$ air. The medium was replaced every $48 \mathrm{~h}$. Myoblast fusion was blocked reversibly by $50 \mu \mathrm{M}$ of BUdR.

Estimation of cell fusion. Cultures were fixed in formalin and stained with gentian violet. Nuclei were counted under a microscope with an ocular grid. The extent of cell fusion was expressed as a fusion index which was the percentage of nuclei found in multinucleated fibers.

Protein and DNA assays. Cultures were placed on ice and rapidly rinsed twice with ice-cold saline solution by means of an aspirator. The cells were immediately covered with ice-cold $5 \%$ trichloroacetic acid (TCA), scraped off and homogenized with a Teflon-pestle glass homogenizer. The homogenates were centrifuged, and the TCA-soluble supernatant fractions were removed for cyclic nucleotide assay. The precipitates were washed twice with $5 \%$ TCA. DNA was extracted from the TCA-insoluble sediments with hot TCA (15) and determined by indol reaction (4) using calf thymus DNA as a standard. The DNA-extracted residues were dissolved in $1 \mathrm{~N} \mathrm{NaOH}$, and protein was assayed by the method of Lowry et al. (6) using bovine serum albumin as a standard.

Cyclic nucleotide assay. The TCA-soluble fractions were washed 3 times with ethylether to remove TCA and evaporated to dryness. The residues were dissolved in $0.05 \mathrm{M}$ acetate buffer (pH 6.8), and aliquots were assayed directly for cAMP and cGMP $(18,19)$ using the radioimmunoassay kit (Schwarz, Mann, N.Y.). Cross-reactivity of the cGMP antiserum with cAMP was $0.005 \%$ and cAMP antiserum with cGMP was $0.002 \%$. The samples from cultured cells did not contain substances interfering with the radioimmunoassay, since the expected values were obtained after addition of known amounts of standard cyclic nucleotides to samples. The preliminary experiment indicated that the corrected values for cyclic nucleotides were approximately equal after purification by Dowex column (10) to the values obtained before purification.

\section{RESULTS}

Three parallel series of cultures were used in this experiment to examine whether cyclic nucleotide changes occur when myoblast fusion was prevented with a specific fusion inhibitor. The first series was a control culture. Cells were cultured in standard

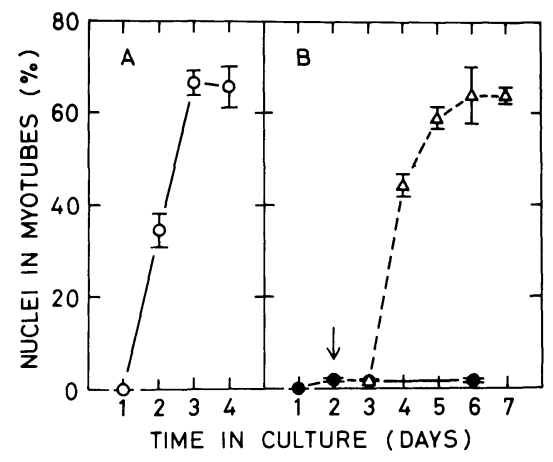

Fig. 1. Effect of BUdR on the time course of myoblast fusion. $\bigcirc$, Control culture; $\bullet$, BUdRtreated culture (BUdR $50 \mu \mathrm{M}) ; \triangle$, BUdR-released culture-medium containing BUdR replaced by normal medium on the second day (arrow). Each point represents the mean of four to five randomly selected microscopic fields of 1,500-3,000 nuclei of a Petri dish. The bars above and below each point represent the range of the standard error. 
medium without inhibitors. In the second series (BUdR-treated cultures), cells were cultured in standard medium containing $50 \mu \mathrm{M}$ of BUdR throughout the experimental period. In the third series (BUdR-released cultures), the cultures were switched to the standard medium from medium containing BUdR on the second day of culture and maintained without BUdR thereafter.

Effect of BUdR on time course of myoblast fusion. Fig. 1 shows the cell fusion kinetics of myoblasts under the three culture conditions. The extent of cell fusion in cultures was estimated by direct microscopic examinations. In the control culture, the onset of cell fusion took place at approximately $45 \mathrm{~h}$ of culture. Fusion index, expressed as the percentage of nuclei found in multinucleated myotubes, increased to $35 \%$ on the second day and reached the maximum level of $70 \%$ by the third day of culture (Fig. 1A). In contrast, cultures initiated in medium containing BUdR at a concentration of $50 \mu \mathrm{M}$ had practically no myotube formation. The fusion index on the sixth day of culture was less than $3 \%$ (Fig. 1B). The inhibition was not complete at lower concentrations of BUdR. The preliminary results indicated that cultures in medium containing $20 \mu \mathrm{M}$ of BUdR had minimal cell fusion and the development of a small number of thin myotubes. When cultures were released from inhibition by replacing the BUdR medium with normal medium, cells started to fuse after a delay of approximately 2 days and eventually fused to the same degree as the control culture grown in normal medium (Fig. 1B).

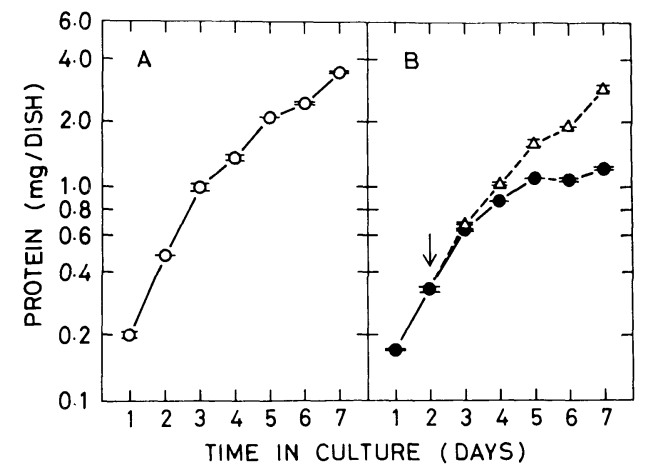

Fig. 2. Effect of BUdR on the time course of protein content. $\bigcirc$, Control culture; $\bullet$, BUdRtreated culture; $\triangle$, BUdR-released culture. Each point represents mean \pm standard error of three different samples. Cells from one to four Petri dishes were combined for each sample.

Effect of BUdR on cell growth. Despite the complete fusion blockade, BUdR at this concentration had little or no effect on macromolecular synthesis of myoblasts. Fig. 2 shows the time courses of protein accumulation in the control, BUdR-treated and BUdR-released cultures. A rapid increase in protein content was observed in all three series. Since the accumulation rate of muscle-specific protein greatly increases after myoblast fusion, e.g., specific activity ( $\mathrm{mU} / \mathrm{mg}$ protein) of creatine kinase in control culture was 71 on the fourth day whereas 199 on the seventh day, the slight inhibitory effect observed in BUdR-treated cultures (Fig. 2B) may be attributed for the most 
part to a failure of myotube formation from myoblasts.

The effect of BUdR on myoblast proliferation was also examined by determining the DNA content in cultures. The ratio of DNA content ( $\mathrm{mg} / \mathrm{dish})$ on the seventh day to that on the first day of culture was 7.6 in both the BUdR-treated culture and the control culture (data not shown).

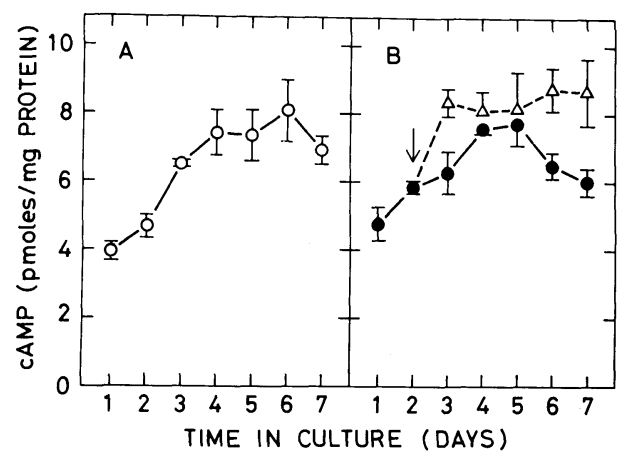

Fig. 3. Effect of BUdR on changes in cAMP intracellular concentration during myogenesis. $\bigcirc$, Control culture; $\bullet$, BUdR-treated culture; $\triangle$, BUdR-released culture. Each point represents mean \pm standard error of three samples.

Changes in $c A M P$ and $c G M P$ levels. After confirming that the appropriate concentration of BUdR blocked myoblast fusion without affecting protein or DNA synthesis, the effects of the reagent on intracellular cAMP and cGMP levels were examined. Fig. 3 shows the time course of intracellular concentrations of cAMP obtained under the three different conditions of culture. In BUdR-treated and BUdR-

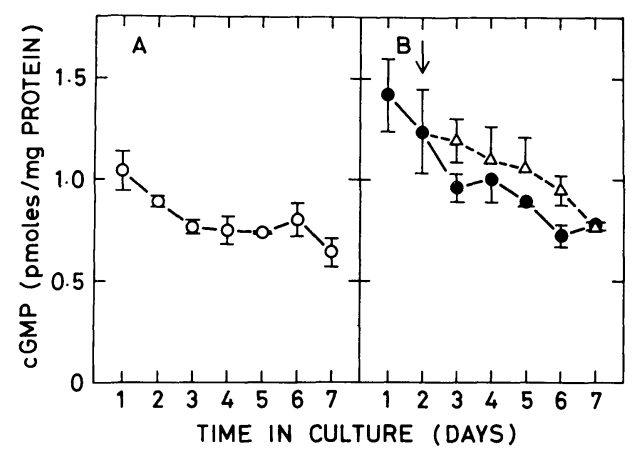

Fig. 4. Effect of BUdR on changes in cGMP intracellular concentration during myogenesis. $\bigcirc$, Control culture; $\bullet, \mathrm{BUdR}$-treated culture; $\triangle$, BUdR-released culture. Each point represents mean \pm standard error of three samples.

released, as well as in control cultures a rapid, approximately 2-fold increase in cAMP concentration was observed during the first few days of culture. Fig. 4 shows the time course of intracellular cGMP concentrations from the same samples used for the 


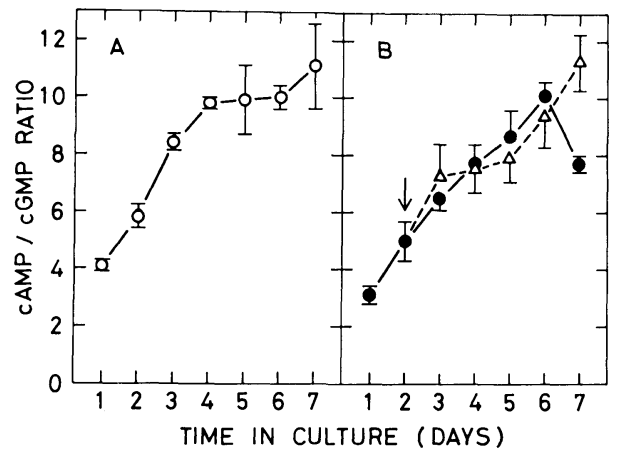

Fig. 5. Effect of BUdR on changes in the ratio of cAMP-to-cGMP. O, Control culture; -, BUdR-treated culture; $\triangle$, BUdR-released culture. Each point represents mean \pm standard error.

cAMP assays. The cGMP level decreased by $30-50 \%$ during the early stage of culture corresponding to the time period during which a marked increase in cAMP level was observed. Because of reciprocal changes in these nucleotides, the ratio of cAMP-tocGMP reflects the changes more clearly. These ratios were calculated and plotted against the days of culture (Fig. 5). In spite of the quite different culture conditions (control, BUdR-treated and BUdR-released cultures), the results from all three experiments were substantially the same. The ratios continued to increase during the early culture stage and in a few days attained levels 3-4 times those of the first day.

\section{DISCUSSION}

The present study reveals that an increase in cAMP and a decrease in cGMP occurs in differentiating muscle cells in which fusion is completely inhibited by BUdR. The mechanism is not understood of how BUdR, an analog of thymidine, reversibly inhibits myoblast fusion without affecting the synthesis of macromolecules required for cell multiplication. However, the following conclusions have been reached by other investigators $(1,2,21)$ : Inhibitory effect of BUdR on differentiation is only observed in cells that pass through $S$ phase; recovery from inhibition requires cell proliferation; and addition of thymidine to the medium prevents the inhibitory effect. These conclusions have been interpreted as indicating that incorporation of BUdR into DNA produces an inhibitory effect on cell differentiation. Incorporation of BUdR into DNA of specific genetic loci $(1,20,23)$ could interfere in the regulation of gene expression or prevent the transcription of messenger RNA responsible for the synthesis of protein necessary for cell fusion.

A correlation has been shown between transient increase in cAMP level and cell fusion in cultured chick muscle cells. The intracellular cAMP level in myoblasts increased 5-6 $\mathrm{h}$ prior to the onset of fusion (26). Moreover, this sequential event was brought forward by prostaglandin $\mathrm{E}_{1}$ without affecting the time interval between the cAMP change and initiation of cell fusion (25). In our previous paper (8), we reported 
a decrease in cGMP, as well as an increase in cAMP levels during the early stage of myogenesis. The most marked increase in the ratio of cAMP-to-cGMP coincided with the period of cell fusion. These findings were confirmed in the present study (Figs. 3-5). A similar observation of an early increase in the cAMP-to-cGMP ratio of cultured muscle cells was recently reported (3). These investigators found a higher cAMP: cGMP ratio after administration of extracts from nerve tissue which can induce differentiation of muscle cells. The possible mechanism for cAMP controlling cell fusion has also been proposed in Sendai virus-induced fusion of Ehrlich ascites tumor cells (11).

The significant increase in the cAMP: cGMP ratio in cultures treated with BUdR (Fig. 5) indicates that cell fusion is not a necessary step for concentration changes in cyclic nucleotides, which means that the intracellular level changes of cyclic nucleotides might be a cause but not an effect of myoblast fusion. Recent evidence $(5,7,9,13)$ reveals that accumulation of muscle-specific protein can occur in cultured myoblasts independent of cell fusion. Therefore, it appears from the present results that a number of events essential for myoblast differentiation, including cell fusion may be triggered by cyclic nucleotides; however the subsequent steps necessary for onset of myoblast fusion are blocked by BUdR.

\section{REFERENCES}

1. Bishoff, R. and H. Holtzer. Inhibition of myoblast fusion after one round of DNA synthesis in 5-bromodeoxyuridine. J. Cell Biol. 44, 134-150, 1970

2. Coleman. J.R., A.W. Coleman and E.J.H. Hartline. A clonal study of the reversible inhibition of muscle differentiation by the halogenated thymidine analog 5-bromodeoxyuridine. Dev. Biol. 19, 527-548, 1969

3. Festoff, B.W. and T.H. Он. Neurotrophic control of cyclic nucleotide levels during muscle differentiation in cell culture. J. Neurobiol. 8, 57-65, 1977

4. KeCK, K. An ultramicro technique for the determination of deoxypentose nucleic acid. Arch. Biochem. Biophys. 63, 446-451, 1956

5. Keller, J.M. and M. NAmeroff. Induction of creatine phosphokinase in cultures of chick skeletal myoblasts without concomitant cell fusion. Differentiation 2, 19-23, 1974

6. Lowry, O.H., N.J. Rosebrough, A.L. Farr and R.J. Randall. Protein measurement with Folin phenol reagent. J. Biol. Chem. 193, 265-275, 1951

7. Merlie, J.P. and F. Gros. In vitro myogenesis: Expression of muscle specific function in the absence of cell fusion. Exp. Cell Res. 97, 406-412, 1976

8. Moriyama, Y., S. Hasegawa and K. Murayama. cAMP and cGMP changes associated with the differentiation of cultured chick embryo muscle cells. Exp. Cell Res. 101, 159-163, 1976

9. Morris, G.E., M. PIPER and R. Cole. Differential effects of calcium ion concentration on cell fusion, cell division and creatine kinase activity in muscle cell cultures. Exp. Cell Res. 99, 106114,1976

10. Murad, F., V. Manganiello and M. Vaughan. A simple, sensitive protein-binding assay for guanosine 3':5'-monophosphate. Proc. Natl. Acad. Sci. USA 68, 736-739, 1971

11. Ohki, K., S. Nakama and A. Asano. Stimulation of virus-induced fusion of Ehrlich ascite tumor cells by 3', 5'-cyclic AMP. Biochem. Biophys. Res. Commun. 67, 331-337, 1975

12. Paterson, B. and R.C. Strohman. Myosin synthesis in cultures of differentiating chicken embryo skeletal muscle. Dev. Biol. 29, 113-138, 1972

13. RePORTER, M. Divergent synthesis of actin and myosin in fused and unfused muscle cells. Biochem. Biophys. Res. Commun. 56, 1086-1092, 1974

14. RichleR, C. and D. YAFFE. The in vitro cultivation and differentiation capacities of myogenic cell lines. Dev. Biol. 23, 1-22, 1970 
15. SCHNeIder, W.C. Phosphorus compounds in animal tissues; extraction and estimation of desoxypentose nucleic acid and of pentose nucleic acid. J. Biol. Chem. 161, 293-303, 1945

16. Schubert, D., H. Tarikas, S. Humphreys, S. Heinemann and J. Patrick. Protein synthesis and secretion in a myogenic cell line. Dev. Biol. 33, 18-37, 1973

17. Shainberg, A., G. Yagil and D. Yaffe. Alterations of enzymatic activities during muscle differentiation in vitro. Dev. Biol. 25, 1-29, 1971

18. Steiner, A.L., A.S. Pagliari, L.R. Chase and D.M. Kipnis. Radioimmunoassay for cyclic nucleotides. II. Adenosine 3', 5'-monophosphate and guanosine 3', 5'-monophosphate in mammalian tissues and body fluids. J. Biol. Chem. 247, 1114-1120, 1972

19. Steiner, A.L., C.W. Parker and D.M. Kipnis. Radioimmunoassay for cyclic nucleotides. I. Preparation of antibodies and iodinated cyclic nucliotides. J. Biol. Chem. 247, 1106-1113, 1972

20. Stellwagen, R.H. and G.M. Tomkins. Preferential inhibition by 5-bromodeoxyuridine of the synthesis of tyrosine aminotransferase in hepatoma cell cultures. J. Mol. Biol. 56, 167-182, 1971

21. Stockdale, F., K. Okazaki, M. Nameroff and H. Holtzer. 5-Bromodeoxyuridine: Effect on myogenesis in vitro. Science 146, 533-535, 1964

22. Wahrmann, J.P., R. Winad and D. Luzzati. Effect of cyclic AMP on growth and morphological differentiation on an established myogenic cell line. Nature New Biol. 245, 112-113, 1973

23. Wishnow, R.M., P. Feist and M.G. Glowalla. The effect of 5-bromodeoxyuridine on steroidogenesis in mouse adrenal tumor cells. Arch. Biochem. Biophys. 161, 275-380, 1974

24. ZALIN, R.J. The relationship of the level of cyclic AMP to differentiation in primary cultures of chick muscle cells. Exp. Cell Res. 78, 152-158, 1973

25. ZALIN, R.J. and R. LEAVER. The effect of a transient increase in intracellular cyclic AMP upon muscle cell fusion. FEBS Lett. 53, 33-36, 1975

26. ZALIN, R.J. and W. Montague. Changes in adenylate cyclase, cyclic AMP, and protein kinase levels in chick myoblasts, and their relationship to differentiation. Cell 2, 103-108, 1974

27. Zalin, R.J. and W. Montague. Changes in cyclic AMP, adenylate cyclase and protein kinase levels during the development of embryonic chick skeletal muscle. Exp. Cell Res. 93, 55-62, 1975 